\title{
Farinha do bagaço de cevada em dietas para a engorda de camarões marinhos
}

\author{
Barley flour in diets for the fattening of marine shrimps
}

\author{
Ruth Gomes de Figueiredo Gadelha' João Paulo de Sousa PradoI \\ José Marcelino Oliveira Cavalheiro ${ }^{I}$
}

\section{RESUMO}

O objetivo deste estudo foi avaliar a qualidade do resíduo de cevada na elaboração de dietas práticas em relação à qualidade nutricional, ao crescimento e à sobrevivência do camarão Litopenaeus vannamei. Foram elaboradas cinco dietas isoprotéicas e isoenergéticas com diferentes proporções da farinha de cevada e do farelo de milho (R1, R2, R3, R4 e R5) e uma ração comercial (R6). Estas foram fornecidas a 150 camarões por um período de 60 dias. O percentual de farinha de cevada utilizado nas rações foi de 0,62; 12,5; 18,7 e 25\%, substituindo o percentual de farelo de milho inicial de 25\%. Camarões com peso inicial de $3 \mathrm{~g}$ foram distribuídos em 30 aquários (cinco camarões por aquários), com $31 \mathrm{~L}$ de água. A farinha elaborada foi analisada para a avaliação da sua qualidade nutricional, apresentando rendimento de 22,63\%. A sobrevivência variou de 88 a $100 \%$, não apresentando diferença significativa. As dietas $R 1$ e $R 5$ resultaram no maior ganho de peso, enquanto que a $R 3$ resultou no menor ganho de peso. Para a taxa de crescimento, as rações $R 1$ (3,47g/60 dias), $R 2$ (3,22g/60 dias), $R 4$ (3,46g/60 dias) e $R 5$ (3,62g/60 dias) apresentaram valores significativos, mas não diferiram estatisticamente $(P>0,05)$. A farinha de cevada em substituição à farinha de milho é recomendada por proporcionar um maior crescimento em camarões juvenis da espécie Litopenaeus vannamei.

Palavras-chave: Litopenaeus vannamei, rendimento, composição e crescimento.

\section{ABSTRACT}

The aim of this study was to evaluate the barley residue in the development of practical diets in relation to nutritional quality, growth and survival of the shrimp Litopenaeus vannamei. Five isoenergetic and isonitrogenous diets were prepared with different proportions of barley flour and corn meal (R1, R2, R3, R4 and R5) and a commercial ration (R6). They were provided to 150 shrimps for a period of 60 days. The percentage of barley meal used in feed was 0.62 , $12.5,18.7$ and $25 \%$ replacing the initial meal maize of $25 \%$. Shrimps with initial weight of $3 \mathrm{~g}$ were distributed into 30 aquariums (five aquariums per shrimp) with $31 \mathrm{~L}$ of water. The flour produced was analyzed for the evaluation of its nutritional quality, giving a yield of $22.63 \%$. Survival ranged from 88 to $100 \%$ and didn't show any significant difference. The $\mathrm{R} 1$ and $R 5$ diets resulted in greater weight gain, while $R 3$ showed lower weight gain. The R1 (3.47g/60 hours), R2 (3.22g/60 hours), A4 (3.46g/60 hours) and $R 5$ (3.62 g/60 hours) growth rate showed significant values, but were not statistically different $(P>0.05)$. The barley flour in place of maize meal is recommended to provide greater growth in juvenile shrimp Litopenaeus vannamei species.

Key words: Litopenaeus vannamei, income, composition and growth.

\section{INTRODUÇÃO}

O camarão marinho da espécie Litopenaeus vannamei, originário da costa sul-americana do Pacífico, apresenta algumas características interessantes para a criação em cativeiro, dentre elas: sua rusticidade, seu rápido crescimento e sua habilidade de desenvolver-se em amplas faixas de salinidade e temperatura, sendo também uma espécie eurihalina (ATWOOD et al., 2003).

Em cultivos semi-intensivos e intensivos das espécies de camarões peneídeos, os alimentos artificiais são fontes importantes de nutrientes, representando um custo de até $60 \%$ do total de

'Universidade Federal da Paraíba (UFPB), 58051970, João Pessoa, PB, Brasil. E-mail: ruthgomesgadelha66@gmail.com. *Autor para correspondência. 
produção (SARAC et al., 1993). São muitos os fatores que afetam os resultados da pesquisa em nutrição animal, dentre estes: a espécie, a idade e o estado fisiológico do animal, as condições e o planejamento experimental, a composição da dieta, a qualidade e o processamento (AKIYAMA et al., 1991).

O Brasil apresenta uma grande variedade de resíduos agrícolas e agroindustriais que são utilizados como fontes nutricionais. Portanto, em função do alto custo e da possível escassez no mercado, diversas pesquisas vêm sendo realizadas utilizando subprodutos como fontes alternativas na substituição de fontes protéicas onerosas na formulação das rações (STEFFENS, 1994; SOUZA, 2004; TEIXEIRA et al., 2006).

Com a finalidade de buscar um novo método alternativo de menor custo em ração para o cultivo do camarão, o presente estudo objetivou elaborar e avaliar quimicamente a farinha de cevada, testando sua utilização com diferentes teores na formulação de dietas para o camarão Litopenaeus vannamei.

\section{MATERIAL E MÉTODOS}

As dietas utilizadas foram isoprotéicas (35\%) e isoenergéticas (3600 Kcal kg-1). Os níveis de proteína bruta (PB) e lipídios foram preestabelecidos em 35 (SMITH et al., 1985) e 7,5\% (VELASCO et al., 2001), respectivamente. O percentual de farinha de bagaço de cevada utilizado nas dietas foi de 0,62, 12,5 18,7 e 25\% em substituição ao percentual utilizado de farelo de milho inicial de 25\%, sendo necessário fazer um balanceamento nas concentrações dos ingredientes. As dietas foram preparadas misturandose os ingredientes secos e, em seguida, acrescentando o óleo e premix previamente diluído em água. Adicionouse água quente $\left( \pm 65^{\circ} \mathrm{C}\right)$ à mistura até formar uma massa consistente, a qual foi processada para serem obtidos peletes de diâmetro igual a 2,0mm. Estes foram secos em estufa com circulação de ar forçada a $65^{\circ} \mathrm{C}\left( \pm 4^{\circ} \mathrm{C}\right)$, durante 24 horas, sendo conservados em sacos de papel à temperatura ambiente até o uso.
Os ingredientes utilizados na formulação das dietas e as próprias dietas experimentais (Tabela 1) tiveram suas composições proximais analisadas segundo INSTITUTO ADOLFO LUTZ (1985) umidade, proteínas e lipídios; AOAC (1993) - cinzas; POMERANZ \& MELOAN (1982) - fibras; RANGANNA (1979) - cálcio e fósforo; BINDLINGMEYER et al. (1984) - aminoácidos, e os carboidratos foram calculados por diferença com a soma dos percentuais dos demais componentes da composição centesimal.

O experimento foi realizado no NUPPA (Núcleo de Pesquisa e Processamento de Alimentos) do Centro de Tecnologia da Universidade Federal da Paraíba. Foi utilizado um sistema de aquários retangulares de polietileno constituído por 30 unidades, com área de 0,205m² (37 x 55,5 x 15cm) e capacidade de 31 litros. Estes aquários foram submetidos à aeração contínua, com renovação de água em torno de $70 \%$ do volume diariamente. Essa água era proveniente sempre do mesmo local de coleta, localizado na praia da Penha, Município de João Pessoa, Paraíba (PB). As dietas foram oferecidas ad libitum uma vez ao dia (10h00min), em quantidade equivalente a $10 \%$ do peso vivo/dia durante todo o experimento (58 dias); esta taxa de arraçoamento teve como finalidade não permitir competição pelo alimento entre os indivíduos, visto que o objetivo dessa fase foi verificar a dieta que proporcionaria melhor ganho de peso (GP) em função do tempo. As sobras de alimento e as fezes foram retiradas por sifonamento três vezes por semana.

Para a análise química das rações, utilizouse o tratamento estatístico (SPSS, 2001), versão 14.0, para constatar influência entre os tratamentos nas rações. O procedimento estatístico utilizado para analisar os dados foram duas medidas descritivas: a taxa de crescimento diária (Taxa Cresc). Diária (\%) = [(Peso após t dias - Peso inicial)/t $] * 100$ e a velocidade de crescimento (Vel. Cresc. em peso $(\%)=[$ (Peso após t dias /Peso no início)]*100/t. O delineamento utilizado para constatar influência entre os tratamentos sobre o crescimento dos camarões foi o modelo de análise de

Tabela 1 - Composição química das rações elaboradas e da ração comercial.

\begin{tabular}{|c|c|c|c|c|c|c|}
\hline Rações & Proteína (\%) & Lipídeos (\%) & Fibras (\%) & Cálcio (\%) & Fósforo (\%) & Carboidratos* (\%) \\
\hline R1 & $35,2 \pm 1,12$ & $7,5 \pm 1,10$ & $5,0 \pm 0,97$ & $2,3 \pm 1,07$ & $0,9 \pm 0,98$ & 49,1 \\
\hline $\mathrm{R} 2$ & $35,4 \pm 0,98$ & $7,5 \pm 0,99$ & $5,0 \pm 1,30$ & $3,5 \pm 1,21$ & $0,8 \pm 1,01$ & 47,8 \\
\hline R3 & $35,6 \pm 1,09$ & $7,5 \pm 1,08$ & $5,5 \pm 0,99$ & $3,5 \pm 1,08$ & $0,8 \pm 1,21$ & 47,1 \\
\hline R4 & $35,1 \pm 0,89$ & $7,5 \pm 1,12$ & $6,7 \pm 1,26$ & $3,5 \pm 1,01$ & $0,8 \pm 1,15$ & 46,4 \\
\hline R5 & $35,5 \pm 1,07$ & $7,5 \pm 0,96$ & $7,0 \pm 1,31$ & $3,5 \pm 1,11$ & $1,3 \pm 1,18$ & 45,2 \\
\hline $\mathrm{R} 6 * *$ & $35,0 \pm 1,03$ & $8,0 \pm 1,24$ & $6,0 \pm 1,03$ & $3,0 \pm 1,06$ & $0,7 \pm 1,06$ & 47,3 \\
\hline
\end{tabular}

* Valor obtido por diferença. * * Ração comercial. 
variância ANOVA, com uma classificação ou um fator (ração). O modelo aditivo de efeito fixo (BOX \& HUNTER, 1983) e a comparação das médias foram realizados pelo teste de TUKEY, considerando o nível de significância de 5\%. A sobrevivência foi calculada com base na diferença entre o número inicial de camarões e o total de indivíduos vivos, no término da pesquisa.

\section{RESULTADOS E DISCUSSÃO}

A temperatura nos aquários variou de 27 a $28^{\circ} \mathrm{C}$, estando dentro dos padrões exigidos pela espécie. $\mathrm{O}$ pH de 7,0 a 8,4 esteve próximo aos limites normais (6,0 a 9,0) segundo MARQUES \& ANDREATTA(1998); a alcalinidade oscilou de $20,6 \mathrm{mg} \mathrm{L}^{-1}$ a $21,8 \mathrm{mg} \mathrm{L}^{-1}$, concentrações consideradas dentro da faixa favorável para o cultivo de organismos aquáticos (BOYD, 1984), e a salinidade foi de $25 \%$. Assim, a qualidade da água ficou dentro dos níveis que não afetam o desenvolvimento do $L$. vannamei.

Em relação aos teores minerais, as rações apresentaram níveis de cálcio iguais a 3,5\%, valor superior ao da ração comercial (R6), com 3,0\%. Para DESHIMARU et al., (1978), quando cultivados em água do mar, os camarões absorvem alguns minerais da água, dentre eles está o cálcio, não sendo, portanto, necessária uma dieta suplementada desse mineral. Quanto aos teores de fósforo, as concentrações apresentadas estão entre os teores exigidos pelo camarão $\boldsymbol{L}$. vannamei (0,34 a 2\%), segundo DAVIS et al. (1993).

A farinha de bagaço de cevada apresentou um rendimento após processamento de $22 \%$, valor bem representativo em seu peso bruto e semelhante aos encontrados por LIMA (1993), com 20\% de rendimento e $21 \%$ do peso original da matéria bruta. Para sua composição centesimal, a farinha de bagaço de cevada apresentou um teor de umidade de 8,9\%, inferior ao observado por LIMA (1993), com 80\%. O teor de proteína apresentou um valor de $22 \%$ similar ao observado pelo Laboratório de Bromatologia da Boviplan e por LIMA (1993) em suas pesquisas, com 17 e 35\%. O lipídeo apresentou-se com valor inferior (6,8\%) ao apresentado por WEST et al. (1994), porém o percentual utilizado para elaboração de rações vai de 8 a 10\% (NUNES, 2000). Esse mesmo autor afirma que, para o teor de fibras, as rações para camarões devem conter no máximo 5 a 8\%.

O aumento na inclusão de farinha de bagaço de cevada nas rações demonstrou que o alimento não apresenta problemas quanto à aceitabilidade pelos camarões, não implicando um desbalanço nutricional das rações avaliadas, visto que foram formuladas com base em nutrientes digestíveis.

A concentração dos diferentes aminoácidos essenciais estimada para a farinha de bagaço de cevada (Tabela 2) indicou maiores concentrações de fenilalanina e valina, quando confrontadas as concentrações dos aminoácidos indicados para camarões peneídeos da espécie Litopenaeus vannamei (GUILLAUME, 1997). Dietas com menores proporções de farelo de soja apresentam melhor desempenho em crescimento. Isso se deve ao fato de que a concentração de quase todos os aminoácidos essenciais aumenta em relação à dieta com maiores concentrações de farinha de peixe, mesmo com a redução dos níveis de metionina. Segundo CYRINO (2000), as diversas fontes protéicas disponíveis no mercado para a formulação das rações não possuem

Tabela 2 - Composição dos aminoácidos analisados na farinha de cevada e comparação dos aminoácidos com os níveis de exigência em ração para camarão.

\begin{tabular}{lccc}
\hline $\begin{array}{l}\text { Aminoácidos. G } 100 \mathrm{~g}^{-1} \\
\text { de proteínas }\end{array}$ & $\begin{array}{c}\text { Farinha de bagaço } \\
\text { cevada }\end{array}$ & $\begin{array}{c}\text { Exigências de Aminoácidos } \\
\text { do L. vannamei* }\end{array}$ & $\begin{array}{c}\text { Percentual suprido pela farinha de bagaço de } \\
\text { cevada nas exigências do Litopenaeus } \\
\text { vannamei* }\end{array}$ \\
\hline Arginina & 1,8 & 13,7 & 13,14 \\
Histidina & 0,9 & 3,8 & 23,68 \\
Isoleucina & 2,3 & 10,7 & 21,5 \\
Lisina & 1,6 & 16,2 & 9,88 \\
Metionina & 0,8 & 14,3 & 5,59 \\
Fenilalanina & 2,6 & 1,4 & 185,71 \\
Treonina & 2,3 & 11,2 & 20,54 \\
Tirosina & 1,4 & 9,0 & 15,56 \\
Valina & 3,2 & 2,0 & 160,00 \\
Leucina & 2,9 & 10,5 & 27,62 \\
\hline
\end{tabular}

*Fonte: AKIYAMA. et al. (1991). 
os mesmos valores nutricionais e níveis de aminoácidos exigidos pelos camarões, tanto quantitativamente, quanto qualitativamente. Entretanto, a farinha de peixe é sem dúvida o ingrediente mais comum na alimentação de camarões, provendo aminoácidos essenciais, como a metionina e lisina, que são normalmente deficientes em proteínas de vegetais (DE SILVA et al., 1994).

A sobrevivência não se diferenciou entre as rações, havendo apenas uma variação de 88 a $100 \%$. Esses resultados foram bastante satisfatórios quando comparados aos registrados por CÉZAR et al. (1998), os quais obtiveram índices de 30 a $80 \%$ ao cultivarem L. vannamei alimentados com ração para galináceos. Outro experimento obteve resultado de $26 \%$ de sobrevivência após 60 dias de cultivo do camarão rosa F. paulensis cultivado em laboratório (JORGENSEN, 2001). Todavia, experimentos efetuados em laboratório, com condições mais estáveis, obtêm taxas de sobrevivência entre 80 e 100\% (SANTOS, 2002).

Ao final do experimento, a ração R3 obteve menor taxa de crescimento diário, rendimento em peso e sobrevivência, enquanto que as outras rações apresentaram-se estatisticamente iguais e com melhor capacidade de crescimento. Esse resultado está de acordo com SCELZO et al. (1999), os quais encontraram taxas de crescimento semanal entre 0,8 e 1,2g. Destacase que tal variação dependerá da qualidade da ração, do local do experimento e das práticas de cultivo. SIQUEIRA et al. (1999), em cultivo com $L$. vannamei alimentados com diferentes rações, obtiveram um ganho de peso de 0,74; 1,65 e 2,55g em 117dias, em tanques de laboratório. Em trabalho de manutenção do povoamento de juvenis de $\boldsymbol{F}$. paulensis com 2,6g em viveiros usando elevadas densidades com cerca de 30 camarões $\mathrm{m}^{-2}$, verificou-se que, após 56 dias de cultivo, os camarões atingiram 9,59g, percebendo-se um ganho de peso variando entre $0,861,06 \mathrm{~g}$ semana $^{-1}$ (WASIELESKY et al., 1994). Já OSTRENSKY \& PESTANA(2000), em um estudo com $\boldsymbol{F}$. paulensis, identificaram que a espécie apresentou uma taxa global de crescimento de $1,35 \mathrm{~g}$ semana $^{-1}$, com uma densidade inicial de 10 camarões $\mathrm{m}^{-2}$ em um cultivo de 78 dias.

As rações R1 e R5 apresentaram as melhores taxas de ganho de peso apenas em relação à R6 (ração comercial). Considerando o uso de técnicas de processamento do material envolvido na fabricação das rações, entende-se que o uso a longo prazo superaria os resultados da ração comercial, demonstrando a viabilidade como alternativa na elaboração de rações para o camarão L. vannamei.

\section{CONCLUSÃO}

A farinha bagaço de cevada pode ser considerada como uma fonte protéica alternativa em dietas para o camarão Litopenaeus vannamei, sendo possível substituir a farinha de milho em até $25 \%$.

\section{REFERÊNCIAS}

ATWOOD, H.L. et al. Survival and growth of Litopenaeus vannamei pos larvae in low-salinity and mixed salt environments. Journal World Aquaculture Society, Los Angeles, v.34, n.4, p.518-523, 2003.

AKIYAMA, D.M. et al. Penaed shrimp nutrition of the commercial feed industry: revised. In: AKIYAMA, D.M.; TAN, R.K.H. (Eds.). Proceedings of the aquaculture feed processing and nutrition workshop. Thailand and Indonesia, Singapore: American Soybean Association, 1991. p.80-98. Disponível em: <http://www.sciencedirect.com/science>. On line. Acesso em: 26 de mai. 2004.

AOAC (Association of Official Analytical Chemists). Official methods of analysis of the Association of Official Analytical Chemists. 1990. 1298p. Disponível em: <http:/ /www.aoac.org/>. Acesso em 06 de mai. 2003.

BINDLINGMEYER, B.A. et al. Rapide analyses of amino acids using pre-colunn derivitington. Journal Chromatograthy, v.336, p.93-104, 1984.

BOYD, C.E. Water qualy managements of ponf fish culture. 2.ed. Amsterdam: Elsevier, 1984. 318p. Disponível em: <http://www.bases.bireme.br/cgi-bin>. On line. Acesso em: 12 de set. 2004.

BOX, W.; HUNTER, P. Statistics for experimenters. New York, John Wyley, 1983. 596-610p.

CÉZAR, J.R.O. et al. Estudo comparativo do cultivo de camarões marinhos Penaeus vannamei e Penaeus subtilis, alimentados com diferentes rações. In: CONGRESSO BRASILEIRO DE ENGENHARIA DE PESCA, 11., 1998, Recife. Anais... Recife: AEP-BR, p.669-675, 1998. Disponível em: $<$ http://www.periodicos.uem.br $>$. On line. Acesso em: 03 de jun. 2003.

CYRINO, J.E.P. Condicionamento alimentar e exigências nutricionais de espécies carnívoras. Piracicaba: ESALQ, 2000. 200p. Disponível em: <http://www.scielo.br>. On line. Acesso em: 26 de jul. 2003.

DAVIS, D.A. et al. Response of Penaeus vannamei to dietary calcium, phosphorus, and calcium: phosphorus ratio. Journal of the World Aquaculture Society, v. 24, p.504-515, 1993. Disponível em: <http://www.sciencedirect.com/science>. On line. Acesso em: 02 de mar. 2004.

DESHIMARU, O. et al. Requirement of prawn for dietary minerals. Nippon Suisan Gakkaishi, v.44, p.907-910, 1978.

DE SILVA, S.S.; ANDERSON, T.A. Fish nutrition in an aquaculture. London: Chapman and Hall, 1994. 254p. Disponível em: <http://www.sciencedirect.com/science>. On line. Acesso em: 15 de out. 2003. 
GUILLAUME, J. Protein and amino acids. In: D'ABRAMO, L.R. et al. Crustacean nutrition - Advances in world aquaculture 6. Baton Rouge, EUA: WAS, 1997. Cap.2, p.26-50.

JORGENSEN, P. Cultivo intensivo de juvenis de camarão rosa Farfantepenaeus paulensis (Perez - Farfante, 1967) em laboratório: avaliação experimental do sistema de engorda. 23: 47-58, 2001. Monografia (Bacharel em Oceanografia) - Fundação Universidade Federal do Rio Grande. Disponível em: <http://www.lei.furg.br/atlantica>. On line. Acesso em: 15 de ago. 2003.

LIMA, M.L.M. Resíduo de cervejaria úmido: formas de conservação e efeitos sobre parâmetros ruminais. 1993. 98f. Dissertação (Mestrado em Ciência Animal e Pastagem) Universidade de São Paulo, Piracicaba,SP. Disponível em: <http:/ /www.periodicos.uem.br>. On line. Acesso em: 18 de jul. 2003.

LUTZ, A. Normas Analíticas do Instituto Adolfo Lutz. Métodos químicos e físicos para análise de alimentos. 3.ed. São Paulo: ITAL, 1985. V.11, 533p.

MARQUES, L.C.; ANDREATTA, E.R. Efeito de freqüência alimentar sobre o consumo de ração e crescimento de juvenis do camarão rosa Penaeus paulensis (Perez-Farfante, 1967). In: CONGRESSO BRASILEIRO DE ENGENHARIA DE PESCA, 11., 1998, Recife. Anais... Recife: AEP-BR, 1998. p.571580, 1998. Disponível em: <http://www.ccarevista.ufc.br>. On line. Acesso em: 16 de set. 2004.

NUNES, A.J.P. Manual Purina de alimentação para camarões marinhos. São Paulo: Paulínia, 2000. 40p. Disponível em: <http://www.nutrimentospurina.com.br/ manuais>. On line. Aceeso em: 22 de fev. 2003.

OSTRENSKY, A.; PESTANA, D. Evaluation of the growth rates of Farfantepenaeus paulensis (Pérez-Farfante, 1967) in ponds. Archives of Veterinary Science, v.5, p.5-15, 2000. Printed in Brazil.

POMERANZ, Y.; MELOAN, C.E. Food analysis: theory and practice. 2.ed. Connecticut: AVI, 1982.

RANGANNA, S. Manual of analysis of fruit and vegetable products. Tata: McGraw-Hill, 634p. 1979.

SANTOS, F.A.P. Efeitos de fontes proteícas e processamento de grãos no desempenho de vacas de leite e digestibilidade dos nutrientes. 2002. 105f. Tese (Livre Docência) - Escola Superior de Agricultura Luiz de Queiroz, Universidade de São Paulo, SP. Disponível em: http:// www.dedalus.usp.br. On line. Acesso em: 24 de ago. 2004.

SARAC, H.Z. et al. Evaluation of Australian protein sources for diets of the black tiger prawn (Penaeus monodon) by proximate analysis and essential amino acid index. In: CARRILLO, M. et al. (Ed.). Conference world aquaculture.
Torremolinos, Spain, 1993. Disponível em: <http:// www.sciencedirect.com>. On line. Acesso em: 21 set. 2004.

SCELZO, M.A.; HERNANDEZ, J. E. Culture experiments of native species of penaeid shrimps in esrthen ponds in Margarita Island, Venezuela, feeding on commercial diets. Aquaculture, v.1, p358-371, 1999. Disponível em: <http://www.elsevier.com>. On line. Acesso em: 06 de fev. 2003.

SIQUEIRA, A.T. et al. Efeitos de diferentes rações no cultivo do camarão cinza Litopenaeus vannamei. In: CONGRESSO BRASILEIRO DE ENGENHARIA DE PESCA, 11., 1999, Recife. Anais... Recife: AEP-BR, 1999. p.785-791. Disponível em: $<$ http:// www.pgpa.ufrpe.br/trabalhos>. On line. Acesso em 08 de fev. 2003

SOUZA, S.R. et al. Diferentes fontes protéicas de origem vegetal para tilápia do Nilo (Oreochromis niloticus L.) durante a reversão sexual. Acta Scientiarum. Animal Sciences, v.26, n.1, p.2128, 2004. Disponível em: <http://www.periodicos.uem.br>. On line. Acesso em: 17 de mai. 2005.

SMITH, L.L. et al. Growth and digestibility of three sizes of Penaeus vannamei Boone: effects of dietary protein level and protein source. Aquaculture, v.46, n.2, p.89-96, 1985. Disponivel em: <http://www.periodicos.uem.br>. On line. Acesso em: 13 de jan. 2003.

STEFFENS, W. Replacing fish meal with poultry by product meal in diets for rainbow trait, Oncarhynchus. Aquaculture, Amsterdan, v.124, p.27-34, 1994. Disponível em: <http:// www.archive.org/>. On line. Acesso em: 09 de out. 2004.

TEIXEIRA, E.A. et al. Substituição de farinhas de peixes em rações para peixes. Revista Brasileira de Reprodução Animal, v.30, n.3/4, p.118-125, 2006. Disponível em: <http:/ /www.cbra.org.br/publicações/rbra>. On line. Acesso em: 25 de mai. 2007

VELASCO, M. et al. Comparison of survival and growth of Litopenaeus vannamei (Crustacea:Decapoda) post larvae reared in static and recirculating culture systems Texas. Journal Science, v.53, n.3, p.227-238, 2001. Disponível em: <http:/ /www.accessmylibrary.com/texas/>. On line. Acesso em: 08 de ago. 2003

WASIELESKY, W.J. et al. Efeitos da amônia sobre o crescimento de pós-larvas de Penaeus paulensis, Perez-Farfante, 1967 (Decapoda: Penaeidae). Nauplius, Rio Grande, v.2, n.1, p.99-105, 1994. Disponível em: <http://www.periodicos.uem.br/>. On line. Acesso em: 10 de abr. 2003.

WEST, J.W. et al. Wet brewers grains for lactating dairy cows during hot, humid weather. Journal of Dairy Science, v.77, p.196-204, 1994. Díspinivel em: <http://www.labmeeting.com>. On line. Acesso em: 11 de jan. 2004. 